\title{
A Substrate Mimetic Approach for Influenza Neuraminidase Inhibitors
}

\author{
Joon Won Jeong, Jae Kuk Kim, Byoung Young Woo, Bok Ju Song, Deok-Chan Ha, and Zaesung No \\ Medicinal Science Division. Korea Research Instinte of Chemical Technology, Daejeon 305-373, Korea \\ ${ }^{\dagger}$ Department of Chemistry. Korea Universit; Seout 136-701. Korea
}

Received Miy 3, 2004

Key Words : Influenza. Neuraminidase inhibitor, Substrate mimetic

Over recent years increased undersianding of the influenza virus replication cycle has allowed investigators to identify several potential molecular targets for drug design. The crystal structures of two major surlace glycoproteins, hemagglutinin ( $\mathrm{I} \wedge$ ) and neuraminidase (N/), expressed by both influenza $\Lambda$ and $B$ viruses have been determined and well characterized. These results have encouraged basic rescarch for the development of specilic and potent inhibitors of $\mathrm{I} / \mathrm{A}$ and $\mathrm{N} \Lambda \mathrm{.}^{1.2}$

The infection cycle of influenza virus starts in the surface epithelial cells of the respiratory tract. IIA mediate the binding of virus to the host cell via terminal sialic acid residue in glycoconjugates and the process of endocylosis. NA, a glycohydrolase, removes the sialic acid from glycoconjugates and lacilitates the release of the virus particles from the inlected cell surlaces during the budding processes and this prevents aggregation of virions by removing sialic acid residues from viral glycoproteins. "

Inhibition of viral replication step should be an eflective method to control and potentially to eradicate viruses from infected tissues. Therefore, inhibition of the viral neuraminidase should prevent the inlluenza virus replication and $\mathrm{N} \Lambda$ has been considered to be a suitable target for designing drugs against influenza viruses.

Since the discovery that $N$-acetylneuraminic acid 1 $(\mathrm{N} \wedge \mathrm{N} \Lambda$ ) had inhibitory activity against $\mathrm{N} \Lambda$, a novel analog, 2,3-didehydro-2-deoxy-N-acetylncuraminic acid 2 (DANA). was synthesized with 1,000 times more activity than $\mathrm{N} \wedge \mathrm{N} \Lambda \mathrm{A}^{+} \mathrm{D} \wedge \mathrm{N} \Lambda$ is considered as a transition state-like analogue binding to the active site of $N \wedge .^{2 b .5}$ On the basis of structural information generated from the X-ray crystallographic study, rationally designed guanidino analogue zanamivir 3 was also active and launched with the name of Relenza ${ }^{3}$. Ilowever, because of its poor oral bioavailibility<smiles>N[C@H]1[C@@H](O)C[C@@](O)(C(=O)O)O[C@]1(O)[C@H](O)[C@H](O)CO</smiles>

1<smiles>[X]C1C=C(C(=O)O)O[C@](C)([C@H](O)[C@H](O)CO)[C@@H]1NC</smiles>

$2 \mathrm{X}=\mathrm{OH}$<smiles>[Y]=NC(=N)N</smiles>

Figure 1 and rapid excretion, zanamivir is administered only by nasal inhalation. ${ }^{56}$ Recently, a new class of compounds having a chemically versatile carbocyclic ring in place of the dihydropyran ring of $\mathrm{D} \Lambda \mathrm{N} \wedge$ was developed as another transition-state mimic by Gilead Sciences. In this series oscltamivir 4 (Tamillu ${ }^{2}$ ) was highly active with good oral bioavailibility, which has been in clinical use since 1999.'

Contrary to this progress, we designed compound 5 for the comparative study of a substrate-mimetic approach to the transition-state mimics. For this study a carbocyclic ring was<smiles>C=CCC(CC)O[C@H]1C[C@@](Cc2ccccc2)(C(=O)O)C[C@H]2N[C@@H]12</smiles>

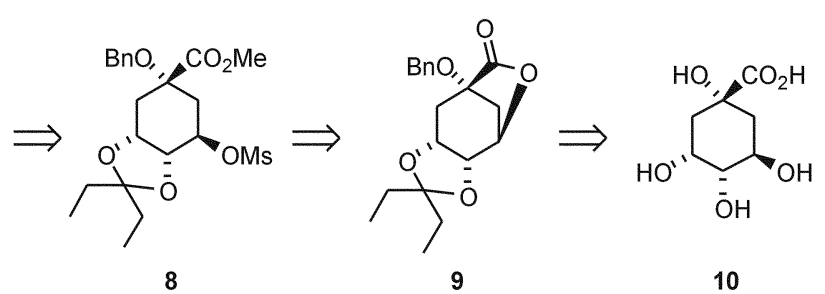

Scheme 1. Retrosynthetic analısis.

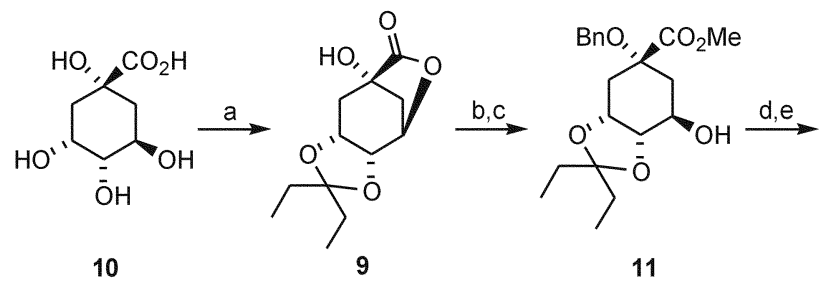

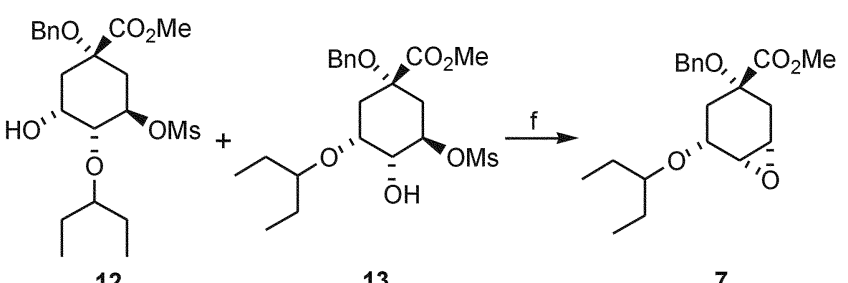

12
Scheme 2. Reagents and conditions: (a) 3-pentanone. DMI: PhII.

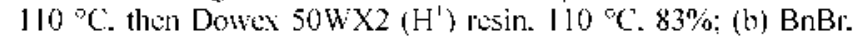
$\mathrm{NaH}$. DMF. $-20^{\circ} \mathrm{C}$ to $0^{\circ} \mathrm{C} .85 \%$ : (c) NaOMe. MeOH. $0^{\circ} \mathrm{C}$ to r.t.

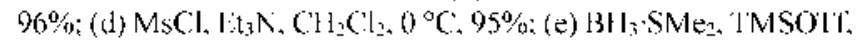

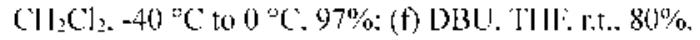


introduced to increase the chemical stability of $\mathbf{5}$, and the same groups as in oseltamivir $\mathbf{4}$ were adapted for the other side chain functionality of this cyclohexane ring except the anomeric carbon. Based on the hydrolysis mechanism of the neuraminidase, ${ }^{8}$ we designed the anomeric $\mathrm{sp}^{3}$ carbon connected to the alkoxy derivatives by ether bond.

As proposed in our retrosynthetic analysis, aziridine 6 was chosen as a key synthetic intermediate and the regioselective ring-opening of 6 using azide ion was planned to construct all the requisite functional groups and chiral centers (Scheme 1). ${ }^{7 \mathrm{~h}}$ Its precursor, epoxide 7 could be derived from the regioselective cleavage of ketal 8 . We envisioned that lactone 9 was generated from the commercially availible (-)quinic acid via ketalization and lactonization. For the synthesis of epoxide 7. (-)-quinic acid $\mathbf{1 0}$ having common structural features of target $\mathbf{5}$ was ketalized using 3pentanone in the presence of Dowex $50 \mathrm{WX} 2\left(\mathrm{H}^{-}\right)$ion resin with concomitant lactonization to give 9 (Scheme 2). ${ }^{9}$ Alcohol 9 was converted to benzyl ether and the resulting lactone was reacted with sodium methoxide to render methyl ester 11. After mesylation of 11, the ketal was reduced with borane dimethylsulfide in the presence of TMSOT $f$ to afford a $20: 1$ inseparable mixture of $\mathbf{1 3}$ and $\mathbf{1 2}$. Then, the mixture was treated with $\mathrm{DBU}$ to give epoxide 7 and the remained 12.

The epoxide ring-opening reaction of 7 was carried out using sodium azide in the presence of ammonium chloride to furnish azide $\mathbf{1 4}$ exclusively by the steric influence of the 3pentyl group (Scheme 3). For the introduction of amino group to $\mathrm{C}-4$ position, aziridine ring-opening was attempted. The hydroxyl group of $\mathbf{1 4}$ was mesylated and the resulting azide was subjected to reduction with triphenylphosphine in the presence of triethylamine and water to furnish aziridine 6 via nucleophilic attack of amino group. To prepare azido amine 16, the aziridine ring-opening of 6 was carried out with the same method used in the epoxide ring-opening of 7 . However, successive nucleophilic attack of the generated
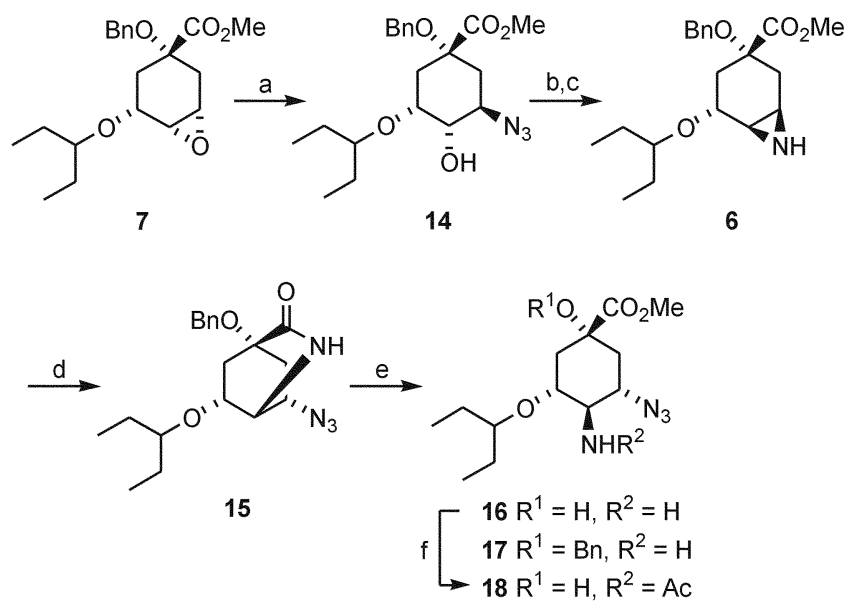

Scheme 3. Reagents and conditions: (a) $\mathrm{NaN}_{3} . \mathrm{NH}_{4} \mathrm{Cl}$. aq $\mathrm{MeOH}$.

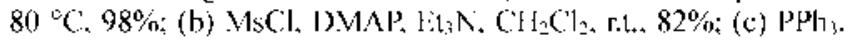
IIII: r.t.. then Lit ${ }_{j} \mathrm{~N}$. II $\mathrm{I}_{2} \mathrm{O}$. r.t. $75 \%$ : (d) $\mathrm{Na} \mathrm{N}_{\text {i. }} \mathrm{NH} \mathrm{H}_{4} \mathrm{Cl}$. ac $\mathrm{MeOll}$. $80{ }^{\circ} \mathrm{C} .74 \%$, (c) $\mathrm{HC}$. $\mathrm{MLOH}$. r.t. $74 \%$ for 16 and $5 \%$ for 17 : (f) $\mathrm{Ac}_{2} \mathrm{O}$. $\mathrm{Ft}_{3} \mathrm{~N}$. C $\left.\mathrm{H}_{2} \mathrm{Cl}\right]_{2}$. r.t.. $94 \%$.

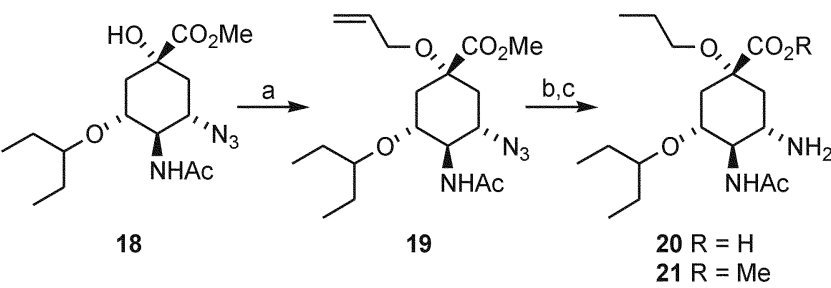

Scheme 4. Reagents and conditions: (a) ally bromide. Bu+.VI. KIIMIDS. I)MF: $30^{\circ} \mathrm{C} .89 \%$ (b) I.iOIIII O. ac MeOII. r.t. 97\%; (c) $\mathrm{II}_{2 .} .10 \% \mathrm{Pd} / \mathrm{C}$. McOH. r.t.. $88 \%$.

amine to the ester group occurred in aqueous condition to furnish lactam 15. Methanolic $\mathrm{HCl}$ for ring-opening of the lactam 15 furnished the desired intermediate 16 with a small amount of benzyl compound 17 . Finally, azido amine 16 was acetylated with acetic anhydride in the presence of triethylamine to furnish the key intermediate $\mathbf{1 8}$ for syntheses of target molecules.

Tertiary alcohol 18 was converted to allyl ether 19 using allyl bromide and KHMDS in the presence of $n-\mathrm{Bu}+\mathrm{NI}$ (Scheme 4). Next, saponification of methyl ester of 19 with lithium hydroxide followed by hydrogenation using palladium charcoal for reduction of azido group and terminal olefin afforded the target molecule 20 . Reduction of 19 using the same hydrogenation condition was performed to give ester 21. Also, benzyl ether $\mathbf{2 4}$ and alcohol $\mathbf{2 2}$ were synthesized from 17 and 18 via similar procedures. The enzymatic inhibitory activities of these carboxylic acids and esters were determined as shown in lable 1.

Other types of ether having different small alkyl group were also synthesized. Alcohol $\mathbf{1 8}$ was converted to methoxymethyl ether 26 using dimethoxymethane and phosphorous oxide, and the following saponification and reduction furnished 27 (Scheme 5). With the same procedure. ethoxymethyl ether 28 and methoxyethyl ether 29 were also prepared.

As shown in Table 1, carboxylic esters 21, 23, and 25 had much less inhibitory activities relative to $\alpha$-hydroxy carboxylic acid 22. The ether group on anomeric carbon also affected the inhibitory activity significantly and simple ether $\mathbf{2 0}$ or alkoxyalkyl ethers $\mathbf{2 7}, \mathbf{2 8}$, and $\mathbf{2 9}$ were more effective inhibitors than the aromatic benzyl ether derivatives $\mathbf{2 4}$ and 25. The best results in terms of the inhibitory activity were attained from simple $n$-propyl ether $\mathbf{2 0}$ and methoxymethyl ether 27. Those results may indicate that the enzymatic surroundings corresponding to the bond-breaking and bondforming anomeric center is very sensitive to the lipophilicity

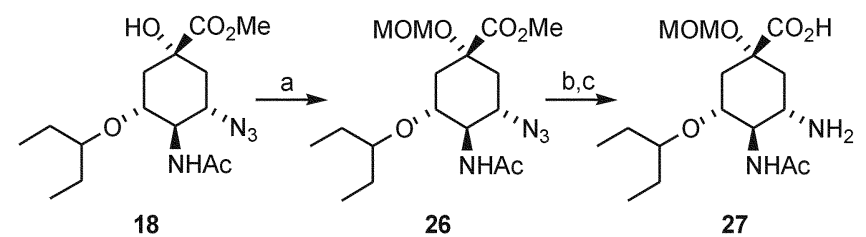

Scheme 5. Reagents and conditions: (a) $\mathrm{Cll}_{2}(\mathrm{OM})_{2} \mathrm{P}_{2} \mathrm{O}_{5}$. Cll $\mathrm{Cl}_{3} \mathrm{Cl}$ r.t. $89 \%$; (b) $\mathrm{LiOH} \mathrm{H}_{2} \mathrm{O}$. aq $\mathrm{M} \mathrm{OH}$. r.t. $98 \%$ : (c) $\mathrm{H}_{2} .10 \% \mathrm{Pd} / \mathrm{C}$. $\mathrm{MeOH}$. r.t. $72 \%$. 
Table 1. Inlluen\%t neuraminidase inhibitions ${ }^{10}$

\begin{tabular}{|c|c|c|c|}
\hline Compd & $\mathrm{R}^{\prime}$ & $\mathrm{R}^{2}$ & $\mathrm{IC}_{\mathrm{s}}(\mu \mathrm{M})$ \\
\hline 22 & 11 & 11 & 261 \\
\hline 23 & 11 & Me & 10762 \\
\hline 24 & $13 n$ & II & 5740 \\
\hline 25 & $13 n$ & Me & 6228 \\
\hline 20 & ${ }_{i l}-\mathrm{P}^{\mathrm{S}}$ & II & 75 \\
\hline 21 & $n-\mathrm{P}+\mathrm{r}$ & $\mathrm{Mc}$ & 1100 \\
\hline 27 & $\mathrm{CH}_{2} \mathrm{OMc}$ & $\mathrm{H}$ & 56 \\
\hline 28 & $\mathrm{CH}_{2} \mathrm{OEt}$ & $\mathrm{H}$ & 219 \\
\hline 29 & $\mathrm{CH}_{2} \mathrm{CH}_{2} \mathrm{OML}$ & $\mathrm{H}$ & 219 \\
\hline
\end{tabular}

of the attached pharmacophores.

In summary, a series of analogs as a substrate mimetic approach for the neuraminidase inhibitor were prepared and their inhibitory activities were determined. Though they were less active than we expected, the selective recognition of the ligands by the enzyme was promising. We are now in progress for further optimization of the side chains of 5 .

Acknowledgements. This work was supported by the Center for Biological Modulators of the 21 st Century Frontier R\&D Program, the Ministry of Science and Technology, Korea.

\section{References}

1. (a) Saul. H. Neru Screntist 1995. 26. (b) Lui. K.-I.: Kondal. A. P. Aim. J. Public /leath 1987.77.712.

2. (a) Varghese, I. I.: Colmen, P. A.J. Wol. Biol. 1995, 22/. 473. (b) Janakiraman. M. N.: White. C.. I..: l.aver, W. (i.: Air. (i. M.: I uo, M. Biohemistry 1994. 33. 8172. (c) Chong. A. K.: P'egg. W. S.: Tay Jor. N. R.: von Itzsteit. M. Eur. I. Biochem. 1992. 207.335. (d) Varghesc. I. V.: Laver. W. G.: Colman. P. M. Nature 1983. 303. 35. (也) Wisly. D. C.: Wilson. I. A.: Skchel. J. J. Nattore 1981. 289. 373. (1) Wilson. I. A.: Skejel. J. J.: Wiely. I). C. Name 1981. 289. 366 .

3. (a) Liu. C.: Ejohelberger M. C.: Compans. R. W.: Air. G. M. $J$. lirol. 1995. 69. 1099. (b) Palese. P.: Jobita. K.: Ueda. M.: Compans. R. W. itrologr 1974. 61. 397.

4. (a) Ifolzer. (. T.: von Itzstein. M.: Jín. B.: Pegs. M. S.: Stewart. W. P. Wu. W.Y. Glyconj, J. 1993. 10\% 40. (b) Meindl. P.: Bodo, (i.: Palese. P.: Schulman, J.: Tuppy, [1. lirolog: 1974, 58 . 457.

5. Tay lor. N. R.: von Itzsteitl. M. J. Hed. Chem. 1994. 37. 616.

6. (a) Fromtling. R. A.: Castaner. J. Dintgs fitt 1996. 2/. 375. (b) von Itzstcin. M.: Wu. Y.: Kok. G. b.: Pegs. . .. S.: Dyason. J. C.: liu. 13.: Van Phan. T.: Symthe. M. I.: White. II. I: Oliver, S. W. Colman. P. ( .. Varghese, V. J.: Cameron. J. M.: Pem. C. R. futtue 1993. 363. 418 .

7. (a) Low. W.: Chen. X.: Kins. C. U. Curr. Wed Chem. 2000. 7. 663. (b) Kitm. C. U.: Lew. W.: Williams. V. A.: Liu. H. T: Zhang. L. J.: Swaminathan. S.: Bischotberger. N.: Chen, M. S.: Mendel, D. B.: Tai, C. Y.: Iaver, W. G.: Stevens. R. C. J. Am. Chem. Soc. 1997. II9. 681 .

8. Bossart-Whitaher. I?: Carson. M.: Babu. Y. S.: Smith. C. D.: Laver. W. G.: Air. G. M. J. Hol. Biol. 1993. 232. 1069.

9. Shing. T. K. M.: Tang. Y. Tetruthe tron 1990. \$6. 6575.

10. Potier. M.: Mameli. 1.: Bélisle. M.: Dallaire. I.: Velançon, S. B. Ind. Biochem. 1979. 287. 